\title{
How Does Growth Follow Differential Convergence Patterns? A Study of the Chinese Regions and Sectors
}

\author{
Yanqing Jiang \\ School of Economics and Finance, Shanghai International Studies University, Shanghai, China \\ Email: yjiang@shisu.edu.cn
}

Received 28 August 2014; revised 16 September 2014; accepted 10 October 2014

Copyright (C 2014 by author and Scientific Research Publishing Inc.

This work is licensed under the Creative Commons Attribution International License (CC BY). http://creativecommons.org/licenses/by/4.0/

\section{(c) (i) Open Access}

\begin{abstract}
This paper focuses on examining differential convergence patterns in productivity growth in China. Our empirical analysis shows that the Chinese provinces exhibit absolute divergence and then absolute convergence respectively during 1990-2000 and 2000-2010. In addition, absolute convergence is present during 1985-1995 and 2000-2010 in the primary sector and during 19952010 in the secondary sector. Our regressions also show that either for the overall regional economy, or for any individual sector, growth in labor productivity exhibits strong convergence. Besides the convergence trends, we also find that the secondary and tertiary sectors have grown significantly faster than the primary sector.
\end{abstract}

\section{Keywords}

Growth, Convergence, Labor Productivity, China

\section{Introduction}

China's post-1978 reform has been widely regarded as a colossal success. Since 1978, the Chinese economy has grown very rapidly, making China one of the world's fastest growing countries. Extrapolations suggest that the absolute size of the Chinese economy may be larger than that of the United States in two or three decades to come. By 2025, China is likely to become the world's largest economic power by almost any measure [1]. However, different regions in China exhibit substantial differences in growth rates and per capita incomes. Huge income disparities, especially the wide gaps in incomes and living standards between coastal and inland areas, are one of the most prominent features in the development process of China.

The substantial disparities in incomes and growth rates in China attract the attention of researchers. Some ar- 
gue that per capita incomes have been diverging across different regions as China is opened up greater foreign trade and foreign investment. Others, however, maintain that many large differences across the regions have declined over time and that poor regions have grown faster than rich ones since the initiation of China's reform. For example, [2]-[5] show a significant increase in interregional income inequality in the reform period, particularly in the late 1980s and 1990s [6]. In contrast, [7] finds that the Chinese national economic policies tend to generate a process of convergence during the 1980s. Similarly, the study of [8] finds that absolute convergence exists in per capita incomes during 1978-1989. The study of [9] also finds similar evidence of absolute convergence using regional data of China for the period 1978-1992.

This paper focuses on examining differential growth and convergence in per worker value added (labor productivity) across different regions and sectors in China. Existing literature tends to suffer from data shortage, poor data quality, limited sample period, and inappropriate methodology used, all of which may significantly bias the conclusions reached. Aiming to provide a more comprehensive and realistic picture of the growth and convergence patterns of the regions and sectors, this paper uses consistent regional and sectoral data to analyze the true tendency of growth and convergence in China over the period of 1985-2010.

The application of the Ramsey growth model as the theoretical framework in this study is motivated by one major fact, which is that the Solow growth model [10] assumes an exogenous and constant saving rate of the economy. Although this assumption may greatly simplify the analysis, the assumed constant and exogenous saving rate may be unrealistic. In a sense, the exogeneity (and constancy) of the saving rate can be viewed as a shortcoming of the Solow growth model. In this study we opt to base our empirical analysis on the theoretical framework of the Ramsey growth model, where the path of consumption and the saving rate are determined by optimizing households and firms that interact on competitive markets. As a result the saving rate is no longer exogenous and does not necessarily have to be constant. In other words, the Ramsey model endogenizes the saving behavior, and we could thus shift our attention from the saving rate per se to underlying factors that influence the saving rate.

The rest of the paper is organized as follows. In Section 2, we present the theoretical framework as the foundation for our subsequent empirical analysis. In Section 3, we set up our econometric model and discuss related issues concerning the variables. In Section 4, we present and analyze our regression results. Finally, conclusions are made in Section 5.

\section{The Theoretical Foundation}

To build the theoretical foundation for our subsequent empirical analysis in this study, in this section we follow the study of [11] in presenting an extended version of the Ramsey growth model [12]-[14] with two types of capital inputs.

We assume that aggregate output is produced with three inputs, that is, two types of capital (say, physical capital and human capital), and a non-reproducible factor, which is raw labor. The production function is assumed to be a Cobb-Douglas form of

$$
Y(t)=A K(t)^{\alpha} H(t)^{\phi}\left[L(t) \mathrm{e}^{g t}\right]^{1-\alpha-\phi}
$$

where $\alpha>0, \phi>0$ and $\alpha+\phi<1 . Y$ is the level of aggregate output, $K$ is the stock of the first type of capital (say, physical capital), $H$ is the stock of the second type of capital (say, human capital), $L$ is the quantity of raw labor, and $A$ is a fixed technology parameter (but is variant across different economies). We assume that raw labor grows exogenously at a constant rate $n$ and the effectiveness of raw labor grows constantly at an exogenous rate of $g$. The intensive form of the production function in (1) is given by

$$
\hat{y}(t)=A \hat{k}(t)^{\alpha} \hat{h}(t)^{\phi}
$$

where we work in terms of per unit of effective labor and, accordingly, define $\hat{y}(t) \equiv Y(t) /\left[L(t) \mathrm{e}^{g t}\right]$, $\hat{k}(t) \equiv K(t) /\left[L(t) \mathrm{e}^{g t}\right]$ and $\hat{h}(t) \equiv H(t) /\left[L(t) \mathrm{e}^{g t}\right]$.

The households own the three production factors and rent them to firms at competitive rental prices. Firms pay a proportional tax at rate $\eta$ on output. The (after-tax) instantaneous profit of the firm (in units of effective labor) is written as ${ }^{1}$

\footnotetext{
${ }^{1}$ We hereinafter drop the argument $t$ (time) wherever possible to avoid cluttering the notations.
} 


$$
\hat{\pi}=(1-\eta) A \hat{k}^{\alpha} \hat{h}^{\phi}-\hat{w}-R_{k} \hat{k}-R_{h} \hat{h}
$$

where $\hat{\pi}$ is the firm's (instantaneous) profit per unit of effective labor, $\hat{w}$ is the wage rate per unit of effective labor, $R_{k}$ is the rental price of the first type of capital (physical capital hereinafter for convenience) and $R_{h}$ is the rental price of the second type of capital (human capital hereinafter for convenience). The firm seeks to maximize the present value of its profits. Without adjustment costs involved, however, maximizing the present value of profits reduces to a problem of maximizing instantaneous profit at each time. Thus the firm equates the marginal products to the rental prices as follows

$$
\begin{gathered}
R_{k}=(1-\eta) \alpha A \hat{k}^{\alpha-1} \hat{h}^{\phi}=(1-\eta) \alpha \hat{y} / \hat{k} \\
R_{h}=(1-\eta) \phi A \hat{k}^{\alpha} \hat{h}^{\phi-1}=(1-\eta) \phi \hat{y} / \hat{h} \\
\hat{w}=(1-\eta) A \hat{k}^{\alpha} \hat{h}^{\phi}-R_{k} \hat{k}-R_{h} \hat{h}
\end{gathered}
$$

These conditions imply that $\hat{\pi}=0$ in (3), as it must be the case in equilibrium.

Infinitely lived households maximize their lifetime utility, which is given by

$$
U=\int_{0}^{\infty} u[c(t)] \mathrm{e}^{n t} \mathrm{e}^{-\rho t} \mathrm{~d} t
$$

where $u[c(t)]=c(t)^{1-\theta} /(1-\theta)$, with $\theta>0, \rho-n-(1-\theta) g>0$, and $c(t)$ is per capita consumption at time $t^{2}$. The households own the physical and human capital and also have the net stock of debt, $\hat{d}$, per unit of effective labor. The budget constraint is given by

$$
\dot{\hat{k}}+\dot{\hat{h}}-\dot{\hat{d}}=\hat{w}+\left(R_{k}-n-g-\delta\right) \hat{k}+\left(R_{h}-n-g-\delta\right) \hat{h}-\hat{c}-(r-n-g) \hat{d}
$$

where $r$ is the real interest rate, and $\hat{c}(t) \equiv c(t) / \mathrm{e}^{g t}{ }^{3}$. Inserting conditions in (4) into the budget constraint in (6) gives us

$$
\dot{\hat{k}}+\dot{\hat{h}}-\dot{\hat{d}}=(1-\eta) A \hat{k}^{\alpha} \hat{h}^{\phi}-(n+g+\delta)(\hat{k}+\hat{h})-\hat{c}-(r-n-g) \hat{d}
$$

Therefore, households maximize utility in (5), subject to (7), given $\hat{k}(0)>0, \hat{h}(0)>0$, and $\hat{d}(0)$. In a closed economy, $\hat{d}=0$ and the real interest rate $r$ must equal the net returns on the two types of capital, $\left(R_{k}-\delta\right)$ and $\left(R_{h}-\delta\right)$. This in turn implies that $\hat{k} / \hat{h}=\alpha / \phi$. The budget constraint can be rewritten in terms of a broad capital stock, $\hat{z} \equiv \hat{k}+\hat{h}$, as

$$
\dot{\hat{z}}=(1-\eta) \tilde{A} \hat{z}^{\alpha+\phi}-(v) \hat{z}-\hat{c}
$$

where $\tilde{A} \equiv A \alpha^{\alpha} \phi^{\phi}(\alpha+\phi)^{-(\alpha+\phi)}$.

The Euler equation is

$$
\dot{\hat{c}} / \hat{c}=(1 / \theta)\left[(1-\eta) \tilde{A}(\alpha+\phi) \hat{z}^{\alpha+\phi-1}-(\delta+\rho+\theta g)\right]
$$

Following basically the same procedure as in a standard Ramsey model, we can derive the steady-state situation as

$$
\hat{z}^{*}=\left(\frac{(1-\eta) \tilde{A}(\alpha+\phi)}{\rho+\delta+\theta g}\right)^{\frac{1}{1-\alpha-\phi}}
$$

and

\footnotetext{
${ }^{2}$ We normalize the initial size of the household at time 0 to unity.

${ }^{3} \mathrm{~A}$ dot over a variable represents the first-order derivative with respect to time. Households receive income from wages and rentals, and spend income on consumption and the accumulation of physical and human capital. Households can borrow or lend at the real interest rate $r$ on the domestic bond market. However, in a closed economy, the debt is zero for the representative household, and $r$ is determined by the equilibrium of saving and investment at the national level. Equation (6) assumes that physical capital and human capital depreciate at the same rate $\delta$.
} 


$$
\hat{y}^{*}=\tilde{A}^{\frac{1}{1-\alpha-\phi}}\left(\frac{(1-\eta)(\alpha+\phi)}{\rho+\delta+\theta g}\right)^{\frac{\alpha+\phi}{1-\alpha-\phi}}
$$

where $\hat{k}^{*}=\hat{z}^{*} \alpha /(\alpha+\phi)$, and $\hat{h}^{*}=\hat{z}^{*} \phi /(\alpha+\phi)$.

Linearizing around the steady state, the adjustment process from an initial position toward the steady state can be described by

$$
\ln \hat{y}\left(t_{2}\right)=\left(1-\mathrm{e}^{-\lambda \tau}\right) \ln \hat{y}^{*}+\mathrm{e}^{-\lambda \tau} \ln \hat{y}\left(t_{1}\right)
$$

where $\hat{y}\left(t_{1}\right)$ is output per unit of effective labor at some initial point in time and $\tau=\left(t_{2}-t_{1}\right)$. Assuming closed Chinese provinces (no capital mobility across regional borders), the speed of convergence, $\lambda$, which depends on the parameters of technology and preferences, can be written as

$$
2 \lambda=\left\{\xi^{2}+4 \cdot\left(\frac{1-\alpha-\phi}{\theta}\right) \cdot(\rho+\delta+\theta g) \cdot\left[\frac{\rho+\delta+\theta g}{\alpha+\phi}-(n+g+\delta)\right]\right\}^{1 / 2}-\xi
$$

where

$$
\xi \equiv \rho-n-(1-\theta) g>0 .
$$

If otherwise we allow for partial capital mobility across provincial borders, that is, we assume that the amount of debt, $\hat{d}$, cannot exceed the quantity of physical capital (the first type of capital) $\hat{k}^{4}$, it can be shown that with this setup, the model predicts a speed of convergence that can be expressed as

$$
2 \lambda_{\text {open }}=\left\{\xi^{2}+4 \cdot\left(\frac{1-\mu}{\theta}\right) \cdot(\rho+\delta+\theta g) \cdot\left[\frac{\rho+\delta+\theta g}{\mu}-(n+g+\delta)\right]\right\}^{1 / 2}-\xi
$$

where $\mu \equiv \phi /(1-\alpha)$, and again $\xi \equiv \rho-n-(1-\theta) g>0$. The speed of convergence described by (12b) is the same value that would arise in a closed province if it had the broad capital share $\mu$, rather than $(\alpha+\phi)$. Since $\mu<\alpha+\phi$ (implied by $\alpha+\phi<1$ ), the credit-constrained open province works like a closed province with a broad capital share that is less than $(\alpha+\phi)$. Therefore, the credit-constrained open province has a higher rate of convergence than the corresponding closed province.

\section{The Econometric Modeling}

Equation (11) above can be rewritten in per capita (per unit of labor, or per worker) terms. Noting that $y(t)=\hat{y}(t) \mathrm{e}^{g t} \quad$ (where we define $y(t) \equiv Y(t) / L(t)$ ), we have

$$
\ln y\left(t_{2}\right)=\mathrm{e}^{-\lambda \tau} \ln y\left(t_{1}\right)+\left(1-\mathrm{e}^{-\lambda \tau}\right) \ln \hat{y}^{*}+g\left(t_{2}-t_{1} \mathrm{e}^{-\lambda \tau}\right)
$$

in which $\hat{y}^{*}$ is given by (10b). Our econometric analysis in this study is directly based on the important idea conveyed by Equation (13). Inserting (10b) into (13) yields

$$
\begin{aligned}
\ln y\left(t_{2}\right)= & \mathrm{e}^{-\lambda \tau} \ln y\left(t_{1}\right)+\left(1-\mathrm{e}^{-\lambda \tau}\right) \frac{\alpha+\phi}{1-\alpha-\phi} \ln (1-\eta)-\left(1-\mathrm{e}^{-\lambda \tau}\right) \frac{\alpha+\phi}{1-\alpha-\phi} \ln (\rho+\delta+\theta g) \\
& +\left(1-\mathrm{e}^{-\lambda \tau}\right) \frac{\alpha+\phi}{1-\alpha-\phi} \ln \tilde{A}+\left(1-\mathrm{e}^{-\lambda \tau}\right) \frac{\alpha+\phi}{1-\alpha-\phi} \ln (\alpha+\phi)+g\left(t_{2}-t_{1} \mathrm{e}^{-\lambda \tau}\right) .
\end{aligned}
$$

We can rewrite Equation (14) in conventional notations of a panel data specification as

$$
y_{i t}=\gamma y_{i, t-1}+\sum_{j=1}^{2} \beta_{j} x_{i t}^{j}+\psi_{t}+u_{i}+v_{i t}
$$

where

\footnotetext{
${ }^{4}$ This assumption introduces an asymmetry between the two types of capital: physical capital can be used as collateral for inter-provincial borrowing, whereas human capital cannot.
} 


$$
\begin{aligned}
& y_{i t} \equiv \ln y\left(t_{2}\right), \quad y_{i, t-1} \equiv \ln y\left(t_{1}\right), \quad \gamma \equiv \mathrm{e}^{-\lambda \tau}, \quad \beta_{1} \equiv\left(1-\mathrm{e}^{-\lambda \tau}\right) \frac{\alpha+\phi}{1-\alpha-\phi}, \quad \beta_{2} \equiv-\left(1-\mathrm{e}^{-\lambda \tau}\right) \frac{\alpha+\phi}{1-\alpha-\phi}, \\
& x_{i t}^{1} \equiv \ln (1-\eta), \quad x_{i t}^{2} \equiv \ln (\rho+\delta+\theta g), \quad u_{i} \equiv\left(1-\mathrm{e}^{-\lambda \tau}\right) \frac{1}{1-\alpha-\phi} \ln \tilde{A}, \\
& \psi_{t} \equiv\left(1-\mathrm{e}^{-\lambda \tau}\right) \frac{\alpha+\phi}{1-\alpha-\phi} \ln (\alpha+\phi)+g\left(t_{2}-t_{1} \mathrm{e}^{-\lambda \tau}\right) .
\end{aligned}
$$

and $v_{i t}$ is the zero-mean idiosyncratic error term that varies across economies and time periods.

As $\alpha$ and $\phi$ are assumed to be fixed across all economies and time periods, the term $\left(1-\mathrm{e}^{-\lambda \tau}\right)[(\alpha+\phi) /(1-\alpha-\phi)] \ln (\alpha+\phi)$ in (14) is a constant and absorbed into the time intercept $\psi_{t}$ in (15). The technology shifter $\tilde{A}$ is fixed for a given economy but is different across economies (i.e. different Chinese provinces in the current study), so the term $\left(1-\mathrm{e}^{-\lambda \tau}\right)[1 /(1-\alpha-\phi)] \ln \tilde{A}$ in (14) constitutes the time-constant province heterogeneity $u_{i}$ in (15). Parameters $\rho$ and $\theta$, which are taken to be exogenous by the Ramsey model, are related to preferences implied by the (lifetime) utility function. The Ramsey model does not explore influencing factors that underlie $\rho$ and $\theta$. For the moment, we assume that $\rho$ and $\theta$ vary over time and across economies. As a result, the term $\ln (\rho+\delta+\theta g)$ enters (15) as an explanatory variable. Similarly, the term $\ln (1-\eta)$, as is also assumed to vary over time and across economies, enters (15) as another explanatory variable.

The main difficulty that confronts us in our econometric analysis is that parameters such as $\eta, \rho$ and $\theta$ are not directly observable. One way to tackle this difficulty is to assume that these parameters (which are allowed to vary across provinces and over time) are not correlated with the initial per capita output and the technology shifter $\tilde{A}$, so that we can subsume the terms involving $\eta, \rho$ and $\theta$ into the idiosyncratic error $v_{i t}$. By doing this, however, we run the risk of giving rise to the omitted variables problem as it is likely that the initial per capita output or the technology parameter $\tilde{A}$ is in fact correlated with $\eta, \rho$ or $\theta$. Another way of dealing with the difficulty is to assume that $\eta, \rho$ and $\theta$ are region-specific but time-constant, so that we can subsume the terms involving $\eta, \rho$ and $\theta$ into the individual province effects term $u_{i}$. By doing so, we can allow for the potential correlation between $\eta, \rho$ and $\theta$ (on the one hand) and the initial per capita output and the technology shifter $\tilde{A}$ (on the other hand), but at the same time run the risk of being unrealistic as the parameters $\eta, \rho$ and $\theta$ may in fact vary over time for any given province.

In view of the tradeoff discussed above, we finally opt to assume that $\rho$ and $\theta$ (i.e. the parameters concerning preferences) are province-specific but time-constant. As a result, we effectively subsume the term $\left(1-\mathrm{e}^{-\lambda \tau}\right)[(\alpha+\phi) /(1-\alpha-\phi)] \ln (\rho+\delta+\theta g)$ into the province heterogeneity term $u_{i}$ alongside with $\left(1-\mathrm{e}^{-\lambda \tau}\right)[1 /(1-\alpha-\phi)] \ln \tilde{A}$. In contrast, for the parameter $\eta$, there is no good reason for assuming a time-constant value of it for any given province. In fact, the very reason to include the term $(1-\eta)$ in our model is to take account of influences (stemming from sources other than technology and preferences) that vary both across regions and over time. Therefore, we opt to subsume the term $\left(1-\mathrm{e}^{-\lambda \tau}\right)[(\alpha+\phi) /(1-\alpha-\phi)] \ln (1-\eta)$ into the idiosyncratic error $v_{i t}$, and tolerate the potential correlation between $(1-\eta)$ and the initial per capita output or the technology shifter.

With the considerations above, Equation (15) reduces to a regression of (the log of) the current per capita output on (the log of) the initial per capita output, the time-constant province heterogeneity term and a time-variant intercept.

\section{Regression Results}

Our sample includes 31 provincial-level regions (provinces for short) in China over the period of 1985-2010 . Relevant data for our regression analysis can be obtained from the various official publications of the National Bureau of Statistics of China ${ }^{6}$. We run both cross sectional and panel data regressions based on the model in (15). In our panel data regressions to come, we partition the entire sample length into five equally spaced time

\footnotetext{
${ }^{5}$ The regions include provinces, ethnic minority autonomous regions, and provincial-level municipalities.

${ }^{6}$ We use real provincial per worker GDP for the per capita level of output in Equation (13).
} 
spans, namely, 1985-1990, 1990-1995, 1995-2000, 2000-2005 and 2005-2010, and employ four time dummy variables (along with a common intercept) to take account of secular changes across different time spans (subperiods).

We first run cross section regressions. Our baseline estimation results are summarized in Table 1. These regressions test unconditional (absolute) convergence in per worker output growth across the Chinese provinces. Specifically, from the results in this table, we can see that during 1990-2000, the estimated coefficient on the lagged dependent variable, $y_{i, t-1}$, is significantly greater than unity, indicating absolute divergence in per worker output growth across the provinces. In contrast, during 2000-2010, the provinces are shown to exhibit absolute convergence in per worker output growth, as indicated by an estimated coefficient on $y_{i, t-1}$ that is significantly lower than unity. Therefore, according the estimation results in Table 1, the basic conclusion we reach is that, in terms growth of per worker output, the Chinese provinces display absolute divergence and then absolute convergence, respectively, during the two consecutive decades, 1990-2000 and 2000-2010.

Next, we examine "club convergence" across the provinces by adding two dummy variables, "East" and "West", to capture the geographical locations of the provinces. "East" equals one if the province belongs to the eastern zone and zero otherwise, and "West" equals one if the province belongs to the western zone and zero otherwise. China is located in the east of Asia. There are oceans to the east and southeast of China, but then there is a gigantic desert in its far north and west and a very high mountain range - the highest in the world-in its southwest. Historically, differences in degrees of regional openness to the outside world can be explained to a large extent by the distances of the regions to the southeast coast of the country. The whole mainland of China is thus divided into three zones - the eastern coastal zone, the central zone and the western zone. The three big zones exhibit systematic differences not only in aspects such as climate and resource endowment, but also in aspects such as culture, policy and exposure to foreign trade and FDI. If all or some of these aspects can be regarded as elements to be included in the technology shifter $A$, or as underlying factors influencing $A$, then in the econometric sense, the zone dummy variables we include would serve as proxy or indicator variables for at least some components captured by $A$. This in a sense justifies our inclusion of zone dummies in the regressions. Our results in Table 2 show that during the decade of 1985-1995, the provinces exhibit significant club convergence, which implies that poor provinces were catching up with the rich provinces within the same geographical zone during that period.

We then rerun the relevant regressions by sector. That is, we run regressions that are parallel to those above, but based on data of each individual sector rather than the overall regional economy. We break up the regional economy into three sectors, i.e. the primary sector, the secondary sector and the tertiary sector. The primary sector (denoted "Sector 1") refers to agriculture, forestry, animal husbandry and fishery and services in support of these industries. The secondary sector (denoted “Sector 2") refers to mining and quarrying, manufacturing, production and supply of electricity, water and gas, and construction. The tertiary sector (denoted "Sector 3") refers to all other economic activities not included in the primary or secondary industries. Results in Table 3 show that during the periods 1985-1995 and 2000-2010, growth in the primary sector displays a trend of absolute convergence across the Chinese provinces, and that during 1995-2010 (that is, during two overlapping periods 1995-2005 and 2000-2010), growth in the secondary sector exhibits a trend of absolute convergence across the provinces. Table 4 examines the case of club convergence across the provinces within the same geographical zone. Our results suggest that during 1985-1995 and 1995-2010 (that is, during two overlapping periods 1995-2005 and 2000-2010), the tertiary sector and the primary sector respectively exhibit club convergence across the provinces within the same geographical zone.

However, we should note that Equation (14) above is associated with the concept of conditional convergence, as the specification contains a region heterogeneity term that conditions the steady state. By definition, conditional convergence means each region convergences to its own steady state. In Table 5, we present our estimation results from Fixed Effects (FE) panel data regressions based on Equation (15). We see that either for the overall regional economy, or for any individual sector, growth in labor productivity (value added per worker) exhibits strong conditional convergence, as reflected by the estimated coefficients on the lagged dependent variable, which are all very significantly lower than unity.

Further, to compare differences in growth rates between different sectors, we now shift to another approach: we pool all the province-sector pairs together as the sample points and use a Least Squares with Dummy Variables (LSDV) method where dummy variables are used to represent each province and each sector. As we have 31 provinces and three sectors, we end up having 93 cross sectional sample points. The dependent variable 
Table 1. Tests for absolute convergence (overall).

\begin{tabular}{|c|c|c|c|c|c|}
\hline \multicolumn{6}{|c|}{ Single cross section regressions (OLS) } \\
\hline \multicolumn{6}{|c|}{ Dependent variable: $y_{i t}$} \\
\hline & 1985-2010 & 1985-1995 & $1990-2000$ & 1995-2005 & $2000-2010$ \\
\hline$y_{i, t-1}$ & $\begin{array}{c}1.057 \\
(0.101)\end{array}$ & $\begin{array}{c}1.044 \\
(0.103)\end{array}$ & $\begin{array}{l}1.264^{*} \\
(0.064)\end{array}$ & $\begin{array}{c}1.029 \\
(0.057)\end{array}$ & $\begin{array}{c}0.839^{*} \\
(0.071)\end{array}$ \\
\hline _cons & $\begin{array}{c}3.004 \\
(0.758)\end{array}$ & $\begin{array}{c}1.259 \\
(0.768)\end{array}$ & $\begin{array}{l}-0.661 \\
(0.519)\end{array}$ & $\begin{array}{c}0.843 \\
(0.520)\end{array}$ & $\begin{array}{c}2.883 \\
(0.681)\end{array}$ \\
\hline$R^{2}$ & 0.7898 & 0.7810 & 0.9305 & 0.9174 & 0.8275 \\
\hline obs & 31 & 31 & 31 & 31 & 31 \\
\hline
\end{tabular}

Notes: Standard errors are in parentheses. An asterisk ${ }^{*}$ denotes that the estimated coefficient on $y_{i, t-1}$ is significantly different from unity at the usual 5\% level. $y_{i t}$ is real provincial per worker GDP in the end year while $y_{i, t-1}$ is that in the initial year, depending on the time period concerned.

Table 2. Tests for club convergence (overall).

\begin{tabular}{|c|c|c|c|c|c|}
\hline \multicolumn{6}{|c|}{ Single cross section regressions (OLS) } \\
\hline \multicolumn{6}{|c|}{ Dependent variable: $y_{i t}$} \\
\hline & $1985-2010$ & 1985-1995 & $1990-2000$ & $1995-2005$ & $2000-2010$ \\
\hline$y_{i, t-1}$ & $\begin{array}{c}0.929 \\
(0.124)\end{array}$ & $\begin{array}{c}0.783^{*} \\
(0.102)\end{array}$ & $\begin{array}{c}1.076 \\
(0.071)\end{array}$ & $\begin{array}{c}1.041 \\
(0.094)\end{array}$ & $\begin{array}{c}0.901 \\
(0.114)\end{array}$ \\
\hline East & $\begin{array}{c}0.230 \\
(0.120)\end{array}$ & $\begin{array}{c}0.390^{*} \\
(0.098)\end{array}$ & $\begin{array}{c}0.230^{*} \\
(0.068)\end{array}$ & $\begin{array}{c}0.015 \\
(0.101)\end{array}$ & $\begin{array}{l}-0.091 \\
(0.135)\end{array}$ \\
\hline West & $\begin{array}{c}0.035 \\
(0.111)\end{array}$ & $\begin{array}{l}-0.018 \\
(0.091)\end{array}$ & $\begin{array}{l}-0.030 \\
(0.058)\end{array}$ & $\begin{array}{c}0.041 \\
(0.079)\end{array}$ & $\begin{array}{c}0.006 \\
(0.106)\end{array}$ \\
\hline _cons & $\begin{array}{c}3.865 \\
(0.924)\end{array}$ & $\begin{array}{c}3.078 \\
(0.761)\end{array}$ & $\begin{array}{c}0.789 \\
(0.571)\end{array}$ & $\begin{array}{c}0.714 \\
(0.833)\end{array}$ & $\begin{array}{c}2.322 \\
(1.067)\end{array}$ \\
\hline$R^{2}$ & 0.8169 & 0.8741 & 0.9560 & 0.9182 & 0.8308 \\
\hline obs & 31 & 31 & 31 & 31 & 31 \\
\hline
\end{tabular}

Notes: Standard errors are in parentheses. An asterisk ${ }^{*}$ denotes that the estimated coefficient on $y_{i, t-1}$ is significantly different from unity and that the estimated coefficients on the other explanatory variables are significantly different from zero, at the usual 5\% level. $y_{i t}$ is real provincial per worker GDP in the end year while $y_{i, t-1}$ is that in the initial year, depending on the time period concerned.

Table 3. Tests for absolute convergence (by sector).

\begin{tabular}{|c|c|c|c|c|c|}
\hline \multicolumn{6}{|c|}{ Single cross section regressions (OLS) } \\
\hline \multicolumn{6}{|c|}{ Dependent variable: $y_{i t}$} \\
\hline & $1985-2010$ & 1985-1995 & $1990-2000$ & 1995-2005 & $2000-2010$ \\
\hline (i) $y_{i, t-1}^{1}$ & $\begin{array}{c}0.936 \\
(0.144)\end{array}$ & $\begin{array}{l}1.262^{*} \\
(0.103)\end{array}$ & $\begin{array}{c}0.914 \\
(0.092)\end{array}$ & $\begin{array}{c}0.873 \\
(0.071)\end{array}$ & $\begin{array}{c}0.793^{*} \\
(0.096)\end{array}$ \\
\hline (ii) $y_{i, t-1}^{2}$ & $\begin{array}{c}0.808 \\
(0.251)\end{array}$ & $\begin{array}{c}0.941 \\
(0.187)\end{array}$ & $\begin{array}{c}1.362 \\
(0.189)\end{array}$ & $\begin{array}{c}0.664^{*} \\
(0.152)\end{array}$ & $\begin{array}{c}0.636^{*} \\
(0.143)\end{array}$ \\
\hline (iii) $y_{i, t-1}^{3}$ & $\begin{array}{c}1.378 \\
(0.229)\end{array}$ & $\begin{array}{c}1.072 \\
(0.205)\end{array}$ & $\begin{array}{c}1.344 \\
(0.187)\end{array}$ & $\begin{array}{c}0.973 \\
(0.098)\end{array}$ & $\begin{array}{c}0.886 \\
(0.117)\end{array}$ \\
\hline obs & 31 & 31 & 31 & 31 & 31 \\
\hline
\end{tabular}

Notes: Standard errors are in parentheses. An asterisk ${ }^{*}$ denotes that the estimated coefficient on $y_{i, t-1}^{j}$ is significantly different from unity at the usual 5\% level. $\quad y_{i t}^{j}$ is real provincial per worker value added in sector $j$ in the end year while $y_{i, t-1}^{j}$ is that in the initial year, depending on the time period concerned. The estimated intercept is not reported in the table for brevity. 
Table 4. Tests for club convergence (by sector).

\begin{tabular}{cccccc}
\hline \multicolumn{5}{c}{ Single cross section regressions (OLS) } \\
\hline \multicolumn{7}{c}{ Dependent variable: $y_{i t}$} \\
\hline & $1985-2010$ & $1985-1995$ & $1990-2000$ & $1995-2005$ & $2000-2010$ \\
\hline (i) $y_{i, t-1}^{1}$ & 0.702 & 1.093 & 0.725 & $0.783^{*}$ & $0.694^{*}$ \\
(ii) $y_{i, t-1}^{2}$ & $(0.174)$ & $(0.122)$ & $(0.099)$ & $(0.097)$ & $(0.141)$ \\
(iii) $y_{i, t-1}^{3}$ & 0.774 & 0.722 & 1.257 & 0.588 & 0.713 \\
obs & $(0.279)$ & $(0.171)$ & $(0.219)$ & $(0.201)$ & $0.173)$ \\
& 0.997 & $0.569^{*}$ & 1.074 & $(0.169)$ & 0.696 \\
\end{tabular}

Notes: Standard errors are in parentheses. An asterisk ${ }^{*}$ denotes that the estimated coefficient on $y_{i, t-1}^{j}$ is significantly different from unity at the usual 5\% level. $y_{i t}^{j}$ is real provincial per worker value added in sector $j$ in the end year while $y_{i, t-1}^{j}$ is that in the initial year, depending on the time period concerned. The estimated coefficients on the geographical dummies and the estimated intercept are not reported in the table for brevity.

Table 5. Tests for conditional convergence (overall and by sector).

\begin{tabular}{ccccc}
\hline \multicolumn{5}{c}{ Panel data regressions (FE) } \\
& Overall & Dependent variable: $y_{i t}$ & Sector 3 \\
\hline & $0.410^{*}$ & Sector 1 & Sector 2 & $0.335^{*}$ \\
$y_{i, t-1}$ & $(0.084)$ & $0.403^{*}$ & $0.508^{*}$ & $(0.087)$ \\
$R^{2} \quad$ (within) & 0.9878 & $(0.094)$ & $0.097)$ & 0.9694 \\
$R^{2}$ (between) & 0.9917 & 0.9668 & 0.9729 & 0.9810 \\
$R^{2}$ (overall) & 0.9163 & 0.9840 & 0.9492 & 0.8921 \\
& 155 & 0.8836 & 155 & 155 \\
\hline
\end{tabular}

Notes: Standard errors are in parentheses. An asterisk ${ }^{*}$ denotes that the estimated coefficient on $y_{i, t-1}$ is significantly different from unity at the usual 5\% level. $\quad y_{i t}$ is the corresponding real per worker GDP (value added) in the end year while $y_{i, t-1}$ is that in the initial year, depending on the time period concerned. The estimated intercepts (i.e. the estimated coefficients on the time dummies as well as the estimated common intercept) are not reported in the table to save space.

is then the log of per worker value added in sector $j$ of province $i$ in the (specified) end year while the (main) explanatory variable is the corresponding lagged dependent variable. In Table 6, we present our estimation results. The primary sector (Sector 1 ) is taken as the default sector, and therefore we need to include two sector dummies to take account of differences in growth across different sectors. The province dummies are also included in the regressions. However, to save space, we do not report the estimated coefficients on the province dummies and the estimated common intercept in the table. We can see that except for the period 1985-1995, growth in the province-sector pairs exhibits significant (conditional) convergence. We also see that, besides the convergence trend, the secondary and tertiary sectors generally experience faster growth than the primary sector, as implied by the significantly positive estimated coefficients on the sector dummies.

Next, in the regressions in Table 7, we keep the (two) sector dummies but drop all the province dummies, aiming to discover a pattern of absolute convergence in regional growth in the individual sectors. Results show that during the period 1995-2010 growth in the primary sector exhibits absolute convergence across the Chinese provinces, and during 1990-2010 growth in the secondary sector displays absolute convergence across the provinces. However, if we further drop the sector dummies to examine region-wide absolute convergence, we end up failing to obtain significant estimates, as can be seen from Table 8 .

From all the regressions above, we see that there is very little evidence for overall region-wide absolute convergence across the Chinese provinces. However, our empirical results provide strong evidence for conditional convergence. This is not surprising as our model above pertains to the case of conditional convergence, in which each economy is expected to converge to its own balanced growth path (steady state). Since different economies 
Table 6. Tests for conditional convergence (by region-sector).

\begin{tabular}{cccccc}
\hline \multicolumn{7}{c}{ Cross section regressions (OLS) } \\
\hline \multicolumn{7}{c}{ Dependent variable: $y_{i t}^{j}$} \\
\hline & $1985-2010$ & $1985-1995$ & $1990-2000$ & $1995-2005$ & $2000-2010$ \\
\hline$y_{i, t-1}^{j}$ & $0.588^{*}$ & 0.892 & $0.463^{*}$ & $0.582^{*}$ & $0.545^{*}$ \\
& $(0.161)$ & $(0.114)$ & $(0.136)$ & $(0.122)$ & $(0.120)$ \\
Sector 2 & $1.145^{*}$ & 0.184 & $1.225^{*}$ & $1.162^{*}$ & $0.982^{*}$ \\
& $(0.239)$ & $(0.169)$ & $(0.192)$ & $(0.188)$ & $(0.229)$ \\
Sector 3 & $0.748^{*}$ & 0.231 & $0.963^{*}$ & $0.764^{*}$ & $0.572^{*}$ \\
$R^{2}$ & $(0.191)$ & $(0.135)$ & $(0.179)$ & $(0.161))$ & $(0.193)$ \\
obs & 0.9606 & 0.9704 & 0.9626 & 0.9655 & 0.9642 \\
\end{tabular}

Notes: Standard errors are in parentheses. An asterisk ${ }^{*}$ denotes that the estimated coefficient on $y_{i, t-1}^{j}$ is significantly different from unity, and that the estimated coefficients on Sector 2 and Sector 3 are significantly different from zero (both at the usual 5\% level). $y_{i t}^{j}$ is the corresponding real per worker GDP (value added) in the end year while $y_{i, t-1}^{j}$ is that in the initial year, depending on the time period concerned. Region and sector dummies are used. The estimated coefficients on the region dummies, as well as the estimate of the common intercept, are not reported in the table for brevity.

Table 7. Tests for differential absolute convergence across sectors (by region-sector).

\begin{tabular}{|c|c|c|c|c|c|}
\hline \multicolumn{6}{|c|}{ Cross section regressions (OLS) } \\
\hline \multicolumn{6}{|c|}{ Dependent variable: $y_{i t}^{j}$} \\
\hline & $1985-2010$ & 1985-1995 & $1990-2000$ & 1995-2005 & $2000-2010$ \\
\hline$y_{i, t-1}^{j}$ & $\begin{array}{c}1.012 \\
(0.115)\end{array}$ & $\begin{array}{c}1.135 \\
(0.090)\end{array}$ & $\begin{array}{c}1.078 \\
(0.081)\end{array}$ & $\begin{array}{c}0.853^{*} \\
(0.060)\end{array}$ & $\begin{array}{c}0.778^{*} \\
(0.068)\end{array}$ \\
\hline Sector 2 & $\begin{array}{c}0.535^{*} \\
(0.185)\end{array}$ & $\begin{array}{l}-0.166 \\
(0.145)\end{array}$ & $\begin{array}{c}0.396^{*} \\
(0.127)\end{array}$ & $\begin{array}{c}0.765^{*} \\
(0.107)\end{array}$ & $\begin{array}{l}0.551^{*} \\
(0.145)\end{array}$ \\
\hline Sector 3 & $\begin{array}{c}0.269 \\
(0.154)\end{array}$ & $\begin{array}{l}-0.044 \\
(0.121)\end{array}$ & $\begin{array}{c}0.196 \\
(0.120)\end{array}$ & $\begin{array}{c}0.430^{*} \\
(0.096)\end{array}$ & $\begin{array}{c}0.213 \\
(0.127)\end{array}$ \\
\hline$R^{2}$ & 0.8852 & 0.8935 & 0.9257 & 0.9388 & 0.9132 \\
\hline obs & 93 & 93 & 93 & 93 & 93 \\
\hline
\end{tabular}

Notes: Standard errors are in parentheses. An asterisk * denotes that the estimated coefficient on $y_{i, t-1}^{j}$ is significantly different from unity, and that the estimated coefficients on Sector 2 and Sector 3 are significantly different from zero (both at the usual 5\% level). $y_{i t}^{j}$ is the corresponding real per worker GDP (value added) in the end year while $y_{i, t-1}^{j}$ is that in the initial year, depending on the time period concerned. Sector dummies are used but region dummies are not used. The estimated common intercept is not reported in the table to save space.

Table 8. Tests for absolute convergence (by region-sector).

\begin{tabular}{cccccc}
\hline \multicolumn{7}{c}{ Cross section regressions (OLS) } \\
\hline \multicolumn{7}{c}{ Dependent variable: $y_{i t}^{j}$} \\
\hline & $1985-2010$ & $1985-1995$ & $1990-2000$ & $1995-2005$ & $2000-2010$ \\
\hline$y_{i, t-1}^{j}$ & 1.286 & 1.058 & 1.262 & 1.179 & 0.970 \\
$R^{2}$ & $(0.052)$ & $(0.039)$ & $(0.041)$ & $(0.041)$ & $(0.036)$ \\
obs & 0.8712 & 0.8899 & 0.9140 & 0.8999 & 0.8900 \\
\hline
\end{tabular}

Notes: Standard errors are in parentheses. An asterisk ${ }^{*}$ denotes that the estimated coefficient on $y_{i, t-1}^{j}$ is significantly different from unity at the usual 5\% level. $\quad y_{i t}^{j}$ is the corresponding real per worker GDP (value added) in the end year while $y_{i, t-1}^{j}$ is that in the initial year, depending on the time period concerned. Sector and region dummies are not used. The estimated common intercept is not reported in the table to save space. 
(provinces) may have vastly different balanced growth paths, we cannot reasonably expect that all provinces are converging to the same, unified growth path.

As a byproduct, we estimate the individual province effects (the estimated coefficients on the province dummies) in our regressions in Table 5. The individual province effects we estimate through this panel data approach can be regarded as a measure of relative total factor productivity (TFP) of the individual provinces (see the model earlier). They may indicate the relative efficiency with which an individual province is able to convert the various production factors into output ${ }^{7}$. If we run regressions by substituting the estimated province effects for the zone dummies in Table 2, we can see that conditioning on the province effects, the provinces exhibit significant (conditional) convergence. This result implies that the cross-region variation in the regional TFP may explain a substantial part of the variation in regional growth rates. In other words, if all the regions were to have the same level of TFP, then there would be a clear pattern of convergence across the regions. However, since in fact the levels of TFP vary vastly across the provinces, we are not able to find evidence for convergence if such convergence is not conditioned on the regional levels of TFP.

Another important result is that from Table 5, we do not find substantially different convergence speeds across the different sectors. However, from Table 6, we see that the growth speeds of the secondary and tertiary sectors are substantially higher than that of the primary sector.

\section{Concluding Remarks}

The substantial disparities in incomes and growth rates in China attract the attention of researchers. This paper focuses on examining differential growth and convergence in per worker value added (labor productivity) across different regions and sectors in China. Aiming to provide a more comprehensive and realistic picture of the growth and convergence patterns of the regions and sectors, this paper uses consistent regional and sectoral data to analyze the true tendency of growth and convergence in China over the period of 1985-2010. Our regression analysis shows that, in terms of overall regional growth of per worker output, the Chinese provinces exhibited absolute divergence and then absolute convergence respectively during the two consecutive decades 1990-2000 and 2000-2010. When we look closer and break up the overall regional growth into growth in the individual sectors, we find that during the periods 1985-1995 and 2000-2010 growth in the primary sector displayed a trend of absolute convergence across the Chinese provinces, and that during 1995-2010 growth in the secondary sector exhibited a trend of absolute convergence. In terms of conditional convergence, our regressions show that either for the overall regional economy, or for any individual sector, growth in labor productivity (value added per worker) exhibits strong convergence. In addition to the convergence trends, we also find that the secondary and tertiary sectors have grown significantly faster than the primary sector.

\section{Acknowledgements}

The author thanks the anonymous reviewers and the editors of the Journal for their helpful comments and suggestions.

\section{References}

[1] Holz, C.A. (2008) China’s Economic Growth 1978-2025: What We Know Today about China’s Economic Growth Tomorrow. World Development, 36, 1665-1691. http://dx.doi.org/10.1016/j.worlddev.2007.09.013

[2] Knight, J. and Song, L. (1993) The Spatial Contribution to Income Inequality in Rural China. Cambridge Journal of Economics, 17, 195-213.

[3] Rozelle, S. (1994) Rural Industrialisation and Increasing Inequality: Emerging Patterns in China's Reforming Economy. Journal of Comparative Economics, 19, 362-391. http://dx.doi.org/10.1006/jcec.1994.1108

[4] Yao, S. (1997) Industrialisation and Spatial Income Inequality in Rural China, 1986-92. The Economics of Transition, 5, 97-112. http://dx.doi.org/10.1111/j.1468-0351.1997.tb00005.x

[5] Yao, S. (1999) Economic Growth, Income Inequality and Poverty in China under Economic Reforms. Journal of Development Studies, 35, 104-130. http://dx.doi.org/10.1080/00220389908422604

[6] Yao, S. and Zhang, Z. (2001) Regional Growth in China under Economic Reforms. Journal of Development Studies, 38, 167-186. http://dx.doi.org/10.1080/00220380412331322301

[7] Hsueh, T. (1994) Pattern of Regional Development in the Peoples Republic of China. Asian Economic Journal, 8, 1-38. 
http://dx.doi.org/10.1111/j.1467-8381.1994.tb00006.x

[8] Gundlach, E. (1997) Regional Convergence of Output per Worker in China: A Neoclassical Interpretation. Asian Economic Journal, 11, 423-442. http://dx.doi.org/10.1111/1467-8381.00046

[9] Raiser, M. (1998) Subsidising Inequality: Economic Reforms, Fiscal Transfers and Convergence across Chinese Provinces. Journal of Development Studies, 34, 1-26. http://dx.doi.org/10.1080/00220389808422518

[10] Solow, R.M. (1956) A Contribution to the Theory of Economic Growth. Quarterly Journal of Economics, 70, 65-94. http://dx.doi.org/10.2307/1884513

[11] Barro, R.J., Mankiw, N.G. and Sala-i-Martin, X. (1995) Capital Mobility in Neoclassical Models of Economic Growth. American Economic Review, 85,103-115.

[12] Ramsey, F. (1928) A Mathematical Theory of Saving. Economic Journal, 38, 543-559. http://dx.doi.org/10.2307/2224098

[13] Cass, D. (1965) Optimum Growth in an Aggregative Model of Capital Accumulation. Review of Economic Studies, 32, 233-240. http://dx.doi.org/10.2307/2295827

[14] Koopmans, T.C. (1965) On the Concept of Optimal Economic Growth. In: Johansen, J., Ed., The Econometric Approach to Development Planning, North Holland, Amsterdam. 
Scientific Research Publishing (SCIRP) is one of the largest Open Access journal publishers. It is currently publishing more than 200 open access, online, peer-reviewed journals covering a wide range of academic disciplines. SCIRP serves the worldwide academic communities and contributes to the progress and application of science with its publication.

Other selected journals from SCIRP are listed as below. Submit your manuscript to us via either submit@scirp.org or Online Submission Portal.
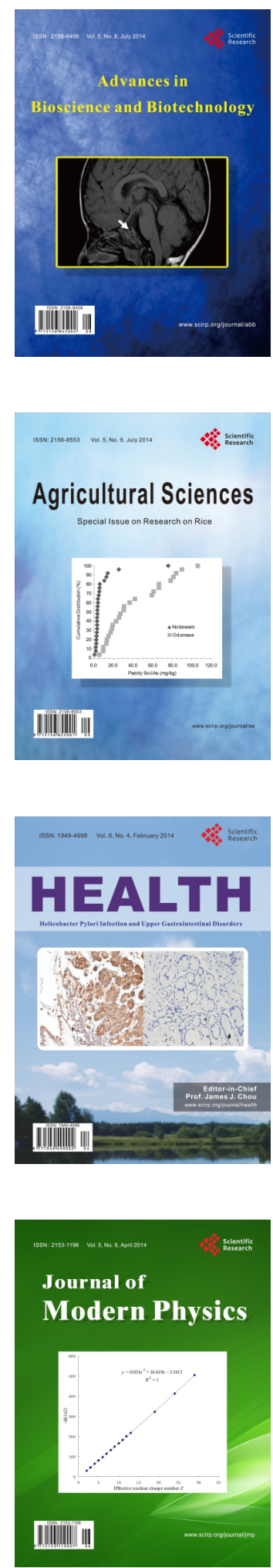
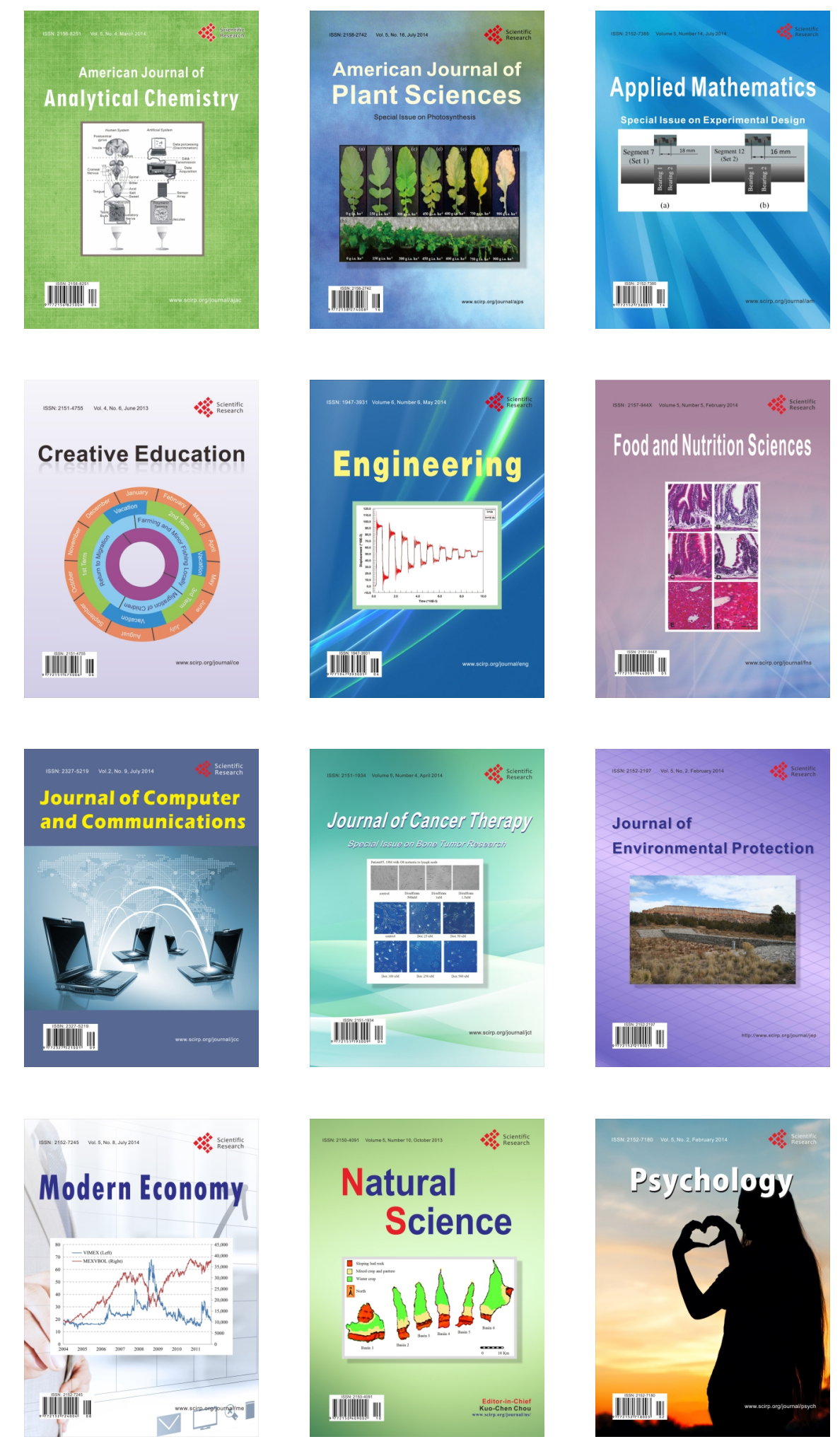